\title{
Utility of Total Lymphocyte Count as an Affordable Surrogate for CD4 Lymphocyte Count in HIV Infected Nepali Patients
}

Sunil Poudel ${ }^{\star}$, Suresh Prajapati, Buddha Laxmi Prajapati, Rama Gyawali, Swosti Acharya, Binod Kumar Yadav and Bishnu Prasad Uppadhya Medical Laboratory Technologist, Civil Service Hospital, Kathmandu, Nepal

\begin{abstract}
Introduction: AIDS is a disease of human immune system caused by Human Immunodeficiency Virus. Immunologically it is defined as the condition characterized by CD4 cell count less than $200 \mathrm{cells} / \mathrm{mm}^{3}$. In developing countries the resource are limited so that CD4 count is not easily available in every parts of the country and is too expensive to afford. The Total lymphocyte count (TLC) has been found to be an inexpensive and useful surrogate marker of CD4 count for staging disease, timing of initiation of Antiretroviral Therapy (ART) and response to ART.
\end{abstract}

Objective: To study the relationship between the T-cell subsets (CD3 and CD4) in HIV patient and to evaluate TLC as a surrogate marker of CD4 T-cell count.

Methods: A total of 303 samples were evaluated from July 2010 to September 2010 at NPHL for this study. The blood sample were analyzed by FACS count and the result were analyzed by SPSS 16.0 to determine sensitivity, specificity, positive predictive value (PPV), negative predictive value (NPV) to find out the relationship between the T cells subsets and evaluate TLC as a surrogate marker of CD4 T cell count for the diagnosis of CD4 count $<200$ cell/ $\mathrm{mm}^{3}$ and $<350 \mathrm{cell} / \mathrm{mm}^{3}$.

Results: There is a strong co-relation between CD4 count and TLC $(r=0.714, p<0.01)$ and CD4 count and CD3 count $(r=0.707, p<0.01)$. A threshold value of $1,400 \mathrm{cell} / \mathrm{mm}^{3}$, we found a maximal combination of sensitivity $(70.1 \%)$, specificity $(81.4 \%)$ and NPV (88.9\%), but PPV is only $56.2 \%$ for a CD4 ${ }^{+}$T cell count $<200 \mathrm{cell} / \mathrm{mm}^{3}$. A CD3 count of $<1000 \mathrm{cell} / \mathrm{mm}^{3}$ would have a maximum combination of sensitivity $(72.7 \%)$, specificity $(81 \%)$ and NPV $(89.7 \%)$ but PPV is only $56.6 \%$ for CD4 T-cell count $<200 \mathrm{cell} / \mathrm{mm}^{3}$.

Conclusion: Total lymphocyte count may provide a simple and cost effective alternative for prioritizing therapy initiation in resources-limited settings. Our study showed a good co-relation (Pearson) of CD4 count with CD3 and TLC, result suggest that, if appropriately validated, judicious application of total lymphocyte counts could overcome one of the practical obstacles to more widespread provision of ART in resource-poor settings.

Keywords: Total lymphocyte count; CD4 count; CD3 count; Nepal; Developing countries

\section{Introduction}

Acquired immune deficiency syndrome (AIDS) is a disease of the human immune system caused by the Human Immunodeficiency Virus (HIV). HIV is a Lentivirus, a member of retrovirus family that can lead to AIDS (Acquired Immuno Deficiency Syndrome), a condition in which immune system begins to fall leading to life threatening opportunistic infection [1]. AIDS is, in fact, not a disease in itself, but a syndrome of a group of disease that weaken the body's defense mechanism [2]. Immunologically, AIDS can be defined as the condition characterized by the CD4 lymphocyte count $<200 / \mu \mathrm{l}$ or $<14 \%$ [3].

HIV causes AIDS by depleting $\mathrm{CD}^{+} \mathrm{T}$ helper lymphocytes. This weakens the immune system and allows OIs. Tlymphocytes are essential to the immune response and without them; the body cannot fight against infections or kill infected and cancerous cells. The mechanism of $\mathrm{CD}^{+} \mathrm{T}$ cell depletion differs in the acute and chronic phases [4].

The HIV/AIDS pandemic has severely affected health development and eroded improvements in life expectancy, particularly in countries with the highest prevalence of infection. Since the first cases of Acquired immunodeficiency syndrome (AIDS) were reported in 1981, infection with Human immunodeficiency virus (HIV) has grown to pandemic proportions resulting in more than 65 million infections and 25 million deaths. At the end of 2006, an estimated 39.5 million people were living with HIV, with Sub-Saharan Africa carrying the highest burden [3] and over 25 Million people have died from AIDS since the first case were described in 1981 [5].
The number of reported HIV infections in Nepal is 6443 (4647 male and 1296 female). The number of AIDS cases is 1025 (male: 747, female: 278) with 311 deaths till date. The facility for CD4 count estimation is available at the National Public Health Laboratory, a government referral laboratory situated at Teku, Kathmandu. In 2005, of the 300 CD4 estimations carried out, more than 100 had CD $4<200 / \mathrm{mm}^{3}$. In the year 2006, of 694 CD 4 estimations, 266 had CD $4<200 / \mathrm{mm}^{3}$. No EQAS is available in the country [4].

As CD4 count is not available at the periphery, the government also compromised to provide the sophisticated instrument due to financial burden. In contrast, we designed this study to find out less expensive and effective surrogate marker of CD4 count which may help in the treatment of HIV/AIDS patient. The value of total lymphocyte count as a surrogate for CD4 has been argued. Viral loads and CD4 counts demand highly skilled laboratory personnel and costly maintenance

*Corresponding author: Sunil Poudel, Medical Laboratory Technologist, Civil Service Hospital, Kathmandu, Nepal, Tel: 097798414251621; E-mail: sooniil@gmail.com

Received January 05, 2014; Accepted February 28, 2014; Published March 11 2014

Citation: Poudel S, Prajapati S, Prajapati BL, Gyawali R, Acharya S, et al. (2014) Utility of Total Lymphocyte Count as an Affordable Surrogate for CD4 Lymphocyte Count in HIV Infected Nepali Patients. J AIDS Clin Res 5: 290. doi:10.4172/2155 6113.1000290

Copyright: ( 2014 Poudel S, et al. This is an open-access article distributed under the terms of the Creative Commons Attribution License, which permits unrestricted use, distribution, and reproduction in any medium, provided the original author and source are credited. 
of sophisticated equipment [6]. In April 2002, WHO recommended the use of absolute lymphocyte count as an alternative marker of CD4. When CD4 cell count is not available or is not affordable, a TLC of less than 1000-1200 lymphocytes $/ \mathrm{mm}^{3}$ could be used as a threshold value to initiate antiretroviral therapy. WHO has suggested TLC count work as a potential marker of immune suppression [7].

In April 2002, WHO released guidelines intended to expand access to ART to 3 million people with HIV/AIDS by 2005 in resource limited setting. The guidelines recommended that if CD4 testing is unavailable, ART is indicated for patient in WHO clinical stage 4 irrespective of TLC and for patient in clinical stage 2 or 3 with a TLC below 1200 cell/ $\mathrm{mm}^{3}[8]$.

\section{Methodology}

\section{Research design}

The design of study was retrospective.

\section{Study site}

The study was conducted in the virology laboratory of the National Public Health Laboratory (NPHL) situated in Kathmandu, Nepal.

\section{Study population}

Out of total samples, 303 samples were analyzed for this study at NPHL from July 2010 to September 2010.

\section{Inclusion criteria}

HIV positive patient was confirmed by ELISA and western blotting.

\section{Sample processing}

Three milliliter of blood sample from each subject was collected in K3 EDTA by using Vacutainer. The collected samples were subjected for CD4, CD3 and total Lymphocyte count within 6 hours of collection at room temperature following standard operating procedure.

\section{Specimen collection and preparation for CD4 count}

Blood sample were aseptically collected by venipuncture into a sterile EDTA (ethylenediamine-tetraacetic acid) BD Vacutainer ${ }^{\mathrm{Ts}}$ blood collection tube. BD Tritest CD3/CD4/CD45 reagent and BD Trucount tubes have been validated with both liquid and dry formulations of EDTA. A minimum of $100 \mu \mathrm{L}$ of whole blood is required for this procedure. The collection tube manufacturer's guidelines for the minimum volume of blood to be collected to ensure proper specimen dilution, especially when determining absolute counts with BD Trucount beads was followed [9].

We obtained a white blood cell (WBC) count and a differential white cell count from the same whole blood sample before staining to ensure that the WBC count is within the linear range or to calculate absolute counts from percentages.

Anticoagulated blood stored at room temperature $\left(20^{\circ}\right.$ to $\left.25^{\circ} \mathrm{C}\right)$ must be stained within 72 hours of draw and then analyzed within 6 hours of staining. If samples are stained within 24 hours of draw, they can be analyzed within 24 hours of staining [9].

\section{Principle}

When whole blood is added to the reagent, the fluorochrome labeled antibodies in the reagent, bind specifically to leucocyte surface antigens. During acquisition, the cells travel past the laser beam and scatter the laser light. The stained cells fluoresce. These scatter and fluorescence signals, detected by the instrument, provide information about the cell's size, internal complexity, and relative fluorescence intensity. BD Tritest reagents use fluorescence triggering, allowing direct fluorescence gating of the lymphocyte population to reduce contamination of unlysed or nucleated red blood cells in the gate. When BD Trucount tubes are used, a precise volume of sample is stained directly in a BD Trucount tube. The lyophilized pellet in the tube dissolves, releasing a known number of fluorescent beads. During analysis, the absolute number $($ cells $/ \mu \mathrm{L})$ of positive cells in the sample can be determined by comparing cellular events to bead events. If appropriate software such as BD Multiset ${ }^{\mathrm{Tw}}$ software is used, absolute counts will be determined by the software. If manually performing data analysis using software such as BD CellQuest ${ }^{\text {mit }}$ software, simply divide the number of positive cellular events by the number of bead events, and then multiply by the BD Trucount bead concentration [9].

\section{Interfering conditions}

Previously fixed and stored patient specimens shouldn't be used. Whole blood samples refrigerated before staining can give aberrant results. Samples obtained from patients taking immunosuppressive drugs can yield poor resolution. 32 Blast cells can interfere with test results. Hemolyzed samples should be rejected [9].

\section{Quality control}

A control sample from a normal adult subjects (hematologically) or a commercially available whole blood control to optimize instrument settings and as a quality control check of the system was run. Commercial controls providing established values for percent positive and absolute counts with each run to assess system were performed. The CD3 vs. SSC dot plot was visually inspected. The T-lymphocyte population should appear as a compact, CD3+ cluster with low SSC. If the T-lymphocyte population is diffuse and if there is little or no separation between it and other clusters the procedure wasn't proceed with analysis. The Ungated CD45 vs. SSC dot plot, Ungated CD3 vs. CD4 dot plot, and Lymphocyte-gated CD3 vs. CD4 dot plot for representative data from a hematologically normal adult sample stained with $\mathrm{CD} 4 / \mathrm{CD} 8 / \mathrm{CD} 3$ in a TruCOUNT Tube was examine [9].

\section{Data analysis}

Statistical Correlation between CD4, CD3 and TLC was assessed by using SPSS software (version 16.0, SPSS, Chicago, USA)

\section{Result}

Overall 303 paired TLC and CD4 ${ }^{+}$T-cell count and paired $\mathrm{CD}^{+}$ $\mathrm{T}$-cell and $\mathrm{CD} 4^{+} \mathrm{T}$ cell count were analyzed to determine the correlation between TLC and CD4, CD3 and CD4 T-cell count and to find out whether TLC can be used to predict CD4 T cell counts in a clinical setting.

Among the 303 patients enrolled, 179(59.1\%) were male, 122 (40.3\%) were female and $2(0.7 \%)$ were third gender. The age ranges from 1 to 88 years (mean 31 years). Among 303 patient observed, $25.4 \%$ (77) had CD4 T cell count $<200$ and 6.3 (19) had CD $4^{+}$T-cell count $<50$, and $41.9 \%$ (127) had $\mathrm{CD}^{+}$count more than 350 cells $/ \mathrm{mm}^{3}$.

Pearson correlations between $\mathrm{CD} 4^{+} \mathrm{T}$ cell with TLC and CD3 cell is summarized in Table 3 . There was a strong correlation between $\mathrm{CD} 4^{+}$ $\mathrm{T}$ cell and TLC ( $\mathrm{r}=0.714)$ as well as between $\mathrm{CD} 4^{+} \mathrm{T}$ cell and $\mathrm{CD} 3$ cells $(\mathrm{r}=0.707)$. 


\begin{tabular}{|c|c|c|c|c|}
\hline TLC & Sensitivity (\%) & Specificity (\%) & PPV (\%) & NPV (\%) \\
\hline 800 & 31.2 & 100 & 100 & 81 \\
\hline 900 & 33.8 & 98 & 86.2 & 81.4 \\
\hline 1000 & 39 & 96.5 & 78.9 & 82.3 \\
\hline 1100 & 45.5 & 95.1 & 76.1 & 93.7 \\
\hline 1200 & 54.5 & 91.6 & 68.9 & 85.5 \\
\hline 1300 & 63.6 & 87.6 & 63.6 & 87.6 \\
\hline $\mathbf{1 4 0 0}$ & $\mathbf{7 0 . 1}$ & $\mathbf{8 1 . 4}$ & $\mathbf{5 6 . 2}$ & $\mathbf{8 8 . 9}$ \\
\hline 1500 & 77.9 & 71.7 & 48.4 & 90.5 \\
\hline 1600 & 77.9 & 65.9 & 43.8 & 89.8 \\
\hline 1700 & 84.4 & 61.1 & 42.5 & 92 \\
\hline 1800 & 84.4 & 58 & 40.6 & 91.6 \\
\hline 1900 & 87 & 49.6 & 37 & 91.8 \\
\hline 2000 & 88.3 & 44.7 & 35.2 & 91.8 \\
\hline
\end{tabular}

Table 1: Combine Sensitivity, Specificity, Positive Predictive Value (PPV) And Negative Predictive Value (NPV) Of TLC Counts For Absolute CD4 ${ }^{+} \mathrm{T}$ Cell Count $<200$ Cells $/ \mathrm{mm}^{3}$

\begin{tabular}{|c|c|c|c|c|}
\hline TLC & Sensitivity (\%) & Specificity (\%) & PPV (\%) & NPV (\%) \\
\hline 800 & 13.6 & 100 & 100 & 45.5 \\
\hline 900 & 15.9 & 99.2 & 96.6 & 46 \\
\hline 1000 & 21 & 99.2 & 97.4 & 47.5 \\
\hline 1100 & 25 & 98.4 & 95.7 & 48.6 \\
\hline 1200 & 33 & 97.6 & 95.1 & 51.2 \\
\hline 1300 & 41.5 & 96.9 & 94.8 & 54.4 \\
\hline 1400 & 51.7 & 96.1 & 94.8 & 58.9 \\
\hline 1500 & 64.8 & 92.1 & 91.9 & 65.4 \\
\hline 1600 & 68.2 & 86.6 & 97.6 & 66.3 \\
\hline 1700 & 74.4 & 82.7 & 85.6 & 70 \\
\hline 1800 & $\mathbf{7 5}$ & $\mathbf{7 7}$ & $\mathbf{8 2 . 5}$ & $\mathbf{6 9 . 2}$ \\
\hline 1900 & 81.8 & 70.9 & 79.6 & 73.8 \\
\hline 2000 & 84.7 & 65.4 & 77.2 & 75.5 \\
\hline
\end{tabular}

Table 2: Combine Sensitivity, Specificity, Positive Predictive Value (PPV) And Negative Predictive Value (NPV) Of TLC Counts for Absolute CD4+ T Cell Count $<350$ Cells $/ \mathrm{mm}^{3}$.

\begin{tabular}{|c|c|c|c|}
\hline & & TLC & CD3 \\
\hline CD4 & Pearson Correlation & 0.714 & 0.707 \\
\hline & Sig. (2-tailed) & 0.00 & 0.00 \\
\hline & $\mathrm{N}$ & 303.0 & 303.0 \\
\hline \multicolumn{2}{l}{ Correlation is significant at 0.01 level. }
\end{tabular}

Table 3: Correlation between CD4 with CD3 and TLC.

Considering a best cut-off value of TLC, that are with the highest Sensitivity and Specificity combination, A TLC $<1400$ cell $/ \mathrm{mm}^{3}$ was found to have a maximal Sensitivity and Specificity for predicting a $\mathrm{CD}^{+} \mathrm{T}$ cell count $<200 \mathrm{cell} / \mathrm{mm}^{3}$. A TLC $<1,800 \mathrm{cell} / \mathrm{mm}^{3}$ was found to have a maximal combination of Sensitivity and Specificity for predicting a $\mathrm{CD}^{+} \mathrm{T}$ cell count of $<350 \mathrm{cell} / \mathrm{mm}^{3}$. When we used a threshold value of $1,400 \mathrm{cell} / \mathrm{mm}^{3}$, we obtain a maximal combination of Sensitivity (70.1\%), Specificity (81.4\%) and NPV (88.9\%), but PPV is only $56.2 \%$ for a $\mathrm{CD} 4^{+} \mathrm{T}$ cell count $<200 \mathrm{cell} / \mathrm{mm}^{3}$. A threshold value of $1,800 \mathrm{cell} / \mathrm{mm}^{3}$ had also maximal combination of Sensitivity $(75 \%)$, Specificity (85\%), PPV (82.5\%) and NPV (69.2\%). A TLC of $<1400$ cell/ $\mathrm{mm}^{3}$ would identified $70.1 \%$ of patient with $\mathrm{CD}^{+} \mathrm{T}$ cell count of $<200$ cell $/ \mathrm{mm}^{3}$. A TLC of $<1800$ identified $75 \%$ of patient with $\mathrm{CD} 4^{+} \mathrm{T}$ cell count of $<350 \mathrm{cell} / \mathrm{mm}^{3}$. The Sensitivity, Specificity, PPV and NPV of various TLC ranges for CD4 ${ }^{+} \mathrm{T}$ cell count $<200$ cells $/ \mathrm{mm}^{3}$ and $\mathrm{CD} 4^{+} \mathrm{T}$ cell count $<350$ cells $/ \mathrm{mm}^{3}$ are listed in Tables 1 and 2 respectively.

TLC of 800 cells $/ \mathrm{mm}^{3}$ has Sensitivity of only $31.2 \%$, Specificity of
$100 \%$, PPV was also $100 \%$ and NPV was $81 \%$. Therefore, using cutoff of $800 \mathrm{cell} / \mathrm{mm}^{3}$ or less will identify only $31.2 \%$ of individuals with $\mathrm{CD}^{+} \mathrm{T}$ cell count $<200$ cell $/ \mathrm{mm}^{3}$ resulting in a risk of false negative results. However, the Specificity at this point is $100 \%$, indicating that all individuals with a TLC less than 800 cells $/ \mathrm{mm}^{3}$ will have a CD4 ${ }^{+} \mathrm{T}$ cell count less than 200 cells $/ \mathrm{mm}^{3}$. To predict $\mathrm{CD} 4^{+} \mathrm{T}$ cell count less than 200 cells $/ \mathrm{mm}^{3}$, TLC cut-point of 1400 cells $/ \mathrm{mm}^{3}$ would result a good Sensitivity, Specificity, PPV and NPV. TLC of 2000 cells $/ \mathrm{mm}^{3}$ would result in a Sensitivity of $88.3 \%$ and Specificity of $44.7 \%$. With an increase in TLC, Sensitivity will be cut off and NPV will increase, but Specificity and PPV will decrease. In order to increase Sensitivity, a higher TLC cut-off is required but would sacrifice Specificity.

\section{$\mathrm{CD} 3$ versus $\mathrm{CD}^{+} \mathrm{T}$ cell count}

A CD3 count of $<1000 \mathrm{cell} / \mathrm{mm}^{3}$ have a maximum combination of Sensitivity (72.7\%), Specificity (81\%) and NPV (89.7\%) but PPV is only $56.6 \%$. A CD3 count of $<1000$ cells/would identify $72.7 \%$ patient with $\mathrm{CD}^{+} \mathrm{T}$ cell count $<200$ cells $/ \mathrm{mm}^{3}$. A CD3 count of $<500$ cells/ $\mathrm{mm}^{3}$ would detect only $13.4 \%$ of patient with $\mathrm{CD}^{+} \mathrm{T}$ cell count $<200$ cells $/ \mathrm{mm}^{3}$. A CD3 count of $<1300$ cells $/ \mathrm{mm}^{3}$ to predict $\mathrm{CD} 4^{+} \mathrm{T}$ cell count $<350$ cells $/ \mathrm{mm}^{3}$ have Sensitivity (76.7\%), Specificity (78\%), PPV (82.8\%) and NPV (70.7\%). CD3 cut-off of $2000 \mathrm{cell} / \mathrm{mm}^{3}$ have a Sensitivity of $97.2 \%$ but Specificity is only $30.7 \%$, so increase risk of false positive results at this cut-off value. There was an increase in Sensitivity and decrease in Specificity as the cut-off for the CD3 increased. A cut off of $1000 \mathrm{cell} / \mathrm{mm}^{3}$ and 1300 cells $/ \mathrm{mm}^{3}$ is a best predicted CD4 ${ }^{+} \mathrm{T}$ cell count $<200$ cells $/ \mathrm{mm}^{3}$ and $<350$ cells $/ \mathrm{mm}^{3}$ respectively (Figures $1-4$ ). The Sensitivity, Specificity, PPV and NPV of various CD3 ranges for $\mathrm{CD} 4^{+} \mathrm{T}$ cell count $<200$ cells $/ \mathrm{mm}^{3}$ and $\mathrm{CD} 4^{+} \mathrm{T}$ cell count $<350$ cells $/ \mathrm{mm}^{3}$ are listed in Tables 1 and 2 respectively.

\section{Discussion}

According to the WHO's general principle to guide decision making about when to initiate ART in resource poor setting, a wider availability of CD4 testing is indispensable. However, the scarcity of this technology shouldn't be a cause to deter treatment while the patient's condition deteriorates if there is access to TLC and knowledge of clinical staging [10].

We found that the total lymphocyte count (TLC) performed well in predicting CD4 count. Our findings suggest TLC, which is relatively

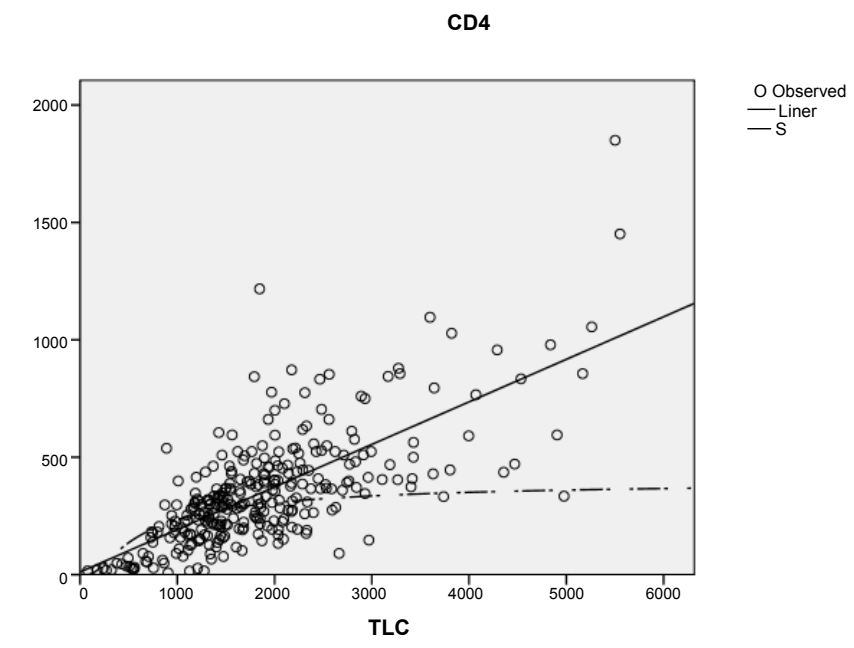

Figure 1: Relationship between CD4 and TLC counts. 


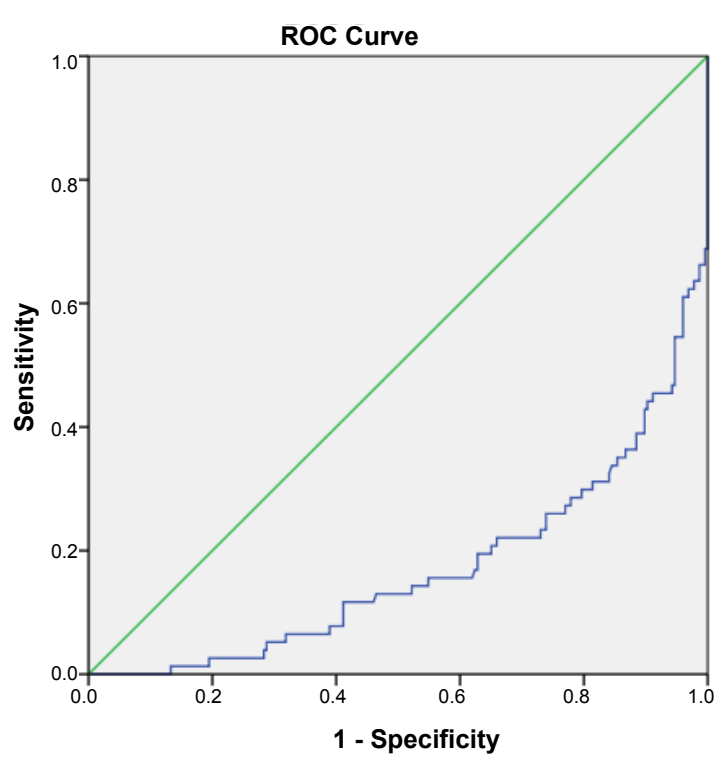

Diagonal segments are produd by ties.

Figure 2: ROC Curve CD4<200/mm $\mathrm{m}^{3}$ with T-cell count of HIV infected patient.

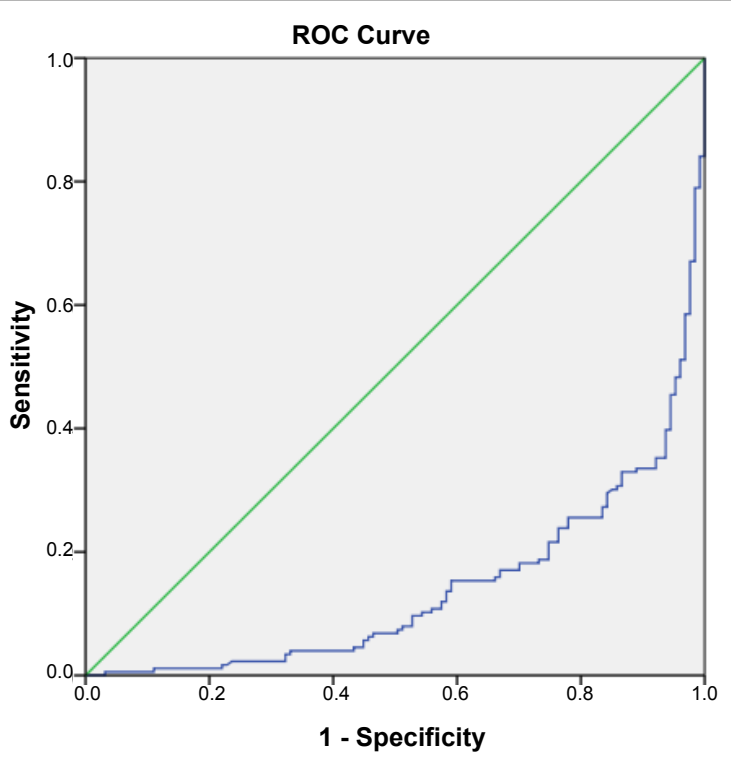

Diagonal segments are produd by ties.

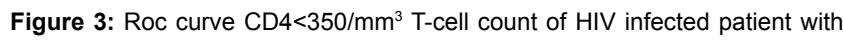
$A \cup C=0.139$.

inexpensive and available, is a reasonably accurate tool that can be used for monitoring the patients' immune status during therapy in addition to determining when patients should start antiretroviral therapy.

Our study has showed the relationship between TLC and CD4 count which is similar to previous study $[7,8,11]$. A relatively high positive correlation has been established between absolute values of TLC and CD4 count or between changes in TLC and CD4 cell count $[6,12]$. Several studies revealed reasonably adequate Sensitivity and Specificity to consider TLC as a surrogate measure for CD4 [6,7,11-14].

This study shows a strong correlation (Pearson) between TLC and CD4 $(r=0.714, p<0.01)$. Similar correlations between TLC and CD4 have been reported in North America, [15] England, [16] Uganda [12] Brazil [7] and India [11]. Despite this strong correlation, our data show that in this population, the WHO guideline of TLC $1200 \mathrm{cells} / \mathrm{mm}^{3}$ is not a sensitive predictor of CD4 below 200 cells $/ \mathrm{mm}^{3}$. (Sensitivity $54.5 \%$, Specificity $91.6 \%$, PPV $68.9 \%$, and NPV $85.5 \%$ ). Therefore, use of the cutoff of 1200 cells $/ \mathrm{mm}^{3}$ or less will identify only fifth of ten individuals with a CD4 below 200 cells $/ \mathrm{mm}^{3}$ resulting in a high risk of false negative results. However, owing to the high Specificity, patients who have CD4 counts $>200$ are unlikely to be treated.

A TLC $<18,00 \mathrm{cell} / \mathrm{mm}^{3}$ was found to have a maximal combination of Sensitivity and Specificity for predicting a CD4 $4^{+} \mathrm{T}$ cell count of $<350$ cell $/ \mathrm{mm}^{3}$. A TLC of $<1800$ identified $75 \%$ of patient with CD4 $4^{+} \mathrm{T}$ cell count of $<350 \mathrm{cell} / \mathrm{mm}^{3}$. The Sensitivity, Specificity, PPV and NPV are $75 \%, 77 \%, 82.5 \%$ and $69.2 \%$ respectively.

It has previously been shown that TLC may represent a valid alternative to CD4 counts in predicting progression to AIDS and death in natural history studies within untreated cohorts. This approach has been used successfully in the context of the WHO staging system [16].

Our study also show a strong correlation (Pearson) between CD3 and CD4 $(\mathrm{r}=0.707, \mathrm{p}<0.01)$. Using CD3 below 1000 cells $/ \mathrm{mm}^{3}$ in the group of patients included in the present study, Sensitivity was $72.7 \%$, Specificity $81 \%$ and PPV were only $56.6 \%$, and NPV was $89.7 \%$. Therefore, use of the cutoff of 1000 cells $/ \mathrm{mm}^{3} \mathrm{CD} 3$ or less will identify seventh of ten individuals with a CD4 below 200 cells $/ \mathrm{mm}^{3}$. However, owing to the high Specificity, patients who have CD4 counts $>200$ are unlikely to be treated.

A CD 3 count of $<1300$ cells $/ \mathrm{mm}^{3}$ to predict $\mathrm{CD} 4^{+} \mathrm{T}$ cell count $<350$ cells $/ \mathrm{mm}^{3}$ would have Sensitivity (76.7\%), Specificity (78\%), PPV $(82.8 \%)$ and NPV (70.7\%). CD3 cut-off of $2000 \mathrm{cell} / \mathrm{mm}^{3}$ would have a Sensitivity of $97.2 \%$ but Specificity is only $30.7 \%$, so increase risk of false positive results at this cut-off value.

This study and others in North America, Europe, India and Africa demonstrate that TLC could serve as a low cost tool for determining

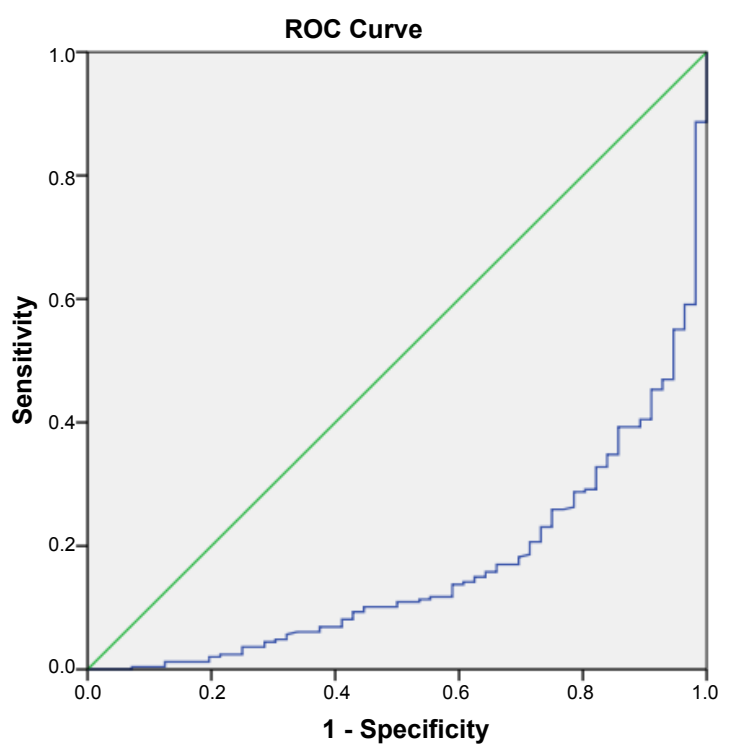

Diagonal segments are produd by ties.

Figure 4: Roc curve CD4 $<500 / \mathrm{mm}^{3}$ T-cell count of HIV infected patient with AUC $=0.163$. 
when to initiate ART in resource-limited countries. Monitoring the progression of HIV in a single patient in Nepal with four CD4 counts per year would cost at least Rs. 10,000. Alternatively, monitoring with TLC four times a year would cost only Rs250. In most cases, patients in Nepal are not able to afford even one CD4 count during the course of their disease. In these patients especially, periodic use of TLC with appropriate cutoffs predicting CD4 count $<200$ or 350 cells $/ \mathrm{mm}^{3}$ would enable timely use of ART along with a better overall sense of the patient's level of immunosuppression and associated risk of OIs.

Nevertheless, this study supports the notion by Gupta and colleagues, as we observed low Sensitivity and Specificity of TLC as an alternate marker to initiate ART. In our study, the Sensitivity and Specificity of TLC $<1200$ to predict CD 4 count $<200$ for adults were $41 \%$ and $83.5 \%$, and these figures were lower than that reported recently from India, 59\% and 94\%, respectively [17].

As it was reported by Jacobson and colleagues, TLC may still be used in resource limited area with the understanding of its low Sensitivity and Specificity. Stebbing and colleagues also indicated that despite minimally less reliability of TLC as a surrogate for CD4, TLC is important tool in the absence of expensive equipment to measure CD4 [18].

Kumarasamy et al. found that a TLC $<1,400$ cells $/ \mathrm{mm}^{3}$ had a $76 \%$ PPV, and a $86 \%$ NPV; it was $73 \%$ sensitive and $88 \%$ specific for a CD 4 count $<200$ cells $/ \mathrm{mm}^{3}$. They also found that a TLC $<1,700$ cells $/ \mathrm{mm}^{3}$ had $86 \%$ PPV, $69 \%$ NPV, and was $70 \%$ sensitive and $86 \%$ specific for a CD 4 count $<350$ cells $/ \mathrm{mm}^{3}$ [11]. Similarly, Blatt et al. demonstrated that a TLC $<1,400$ cells $/ \mathrm{mm}^{3}$ was $80 \%$ sensitive and $90 \%$ specific for a CD4 count $<200$ cells $/ \mathrm{mm}^{3}$ [19].

Our study is also supported by Post et al. who evaluated TLC and CD4+ T-cell counts of 831 HIV/AIDS patients from South Africa as predictors of developing AIDS or death. They concluded that a TLC of $<1,250 \mathrm{cell} / \mathrm{mm}^{3}$ and a CD4+ T-cell count of $<200$ cells $/ \mathrm{mm}^{3}$ were equal predictors of disease progression and could be used as a cutoff for starting prophylaxis [13].

Angelo ALD et al. found that with a threshold value of 1,700 cells/ $\mathrm{mm}^{3}$ for TLC, the positive predictive value was only $31.1 \%$ for CD $4<200$ cells $/ \mathrm{mm}^{3}$, and the Sensitivity was $76.3 \%$. The negative predictive value was $93.1 \%$, with a Specificity of $65.2 \%$. A better result was observed for the limit of 350 cells $/ \mathrm{mm}^{3}$, which presented the best correlation with a TLC of 1,700 cells $/ \mathrm{mm}^{3}$ (SE=59.4\%, SPE=75.8\%) [7].

Similarly a TLC of $2 \times 10^{9}$ cells/L or less had a Sensitivity of 90.3\% to detect patients with a CD4 ${ }^{+}$T-cell count $<200$ cells $/ \mathrm{mm}^{3}$, but a Specificity of only $53.7 \%$. As the TLC cutoff value was lowered, Specificity increased but Sensitivity decreased. A TLC of $2 \times 10^{9}$ cells/L or less had a Sensitivity of only $58.73 \%$ to detect patients with a $\mathrm{CD} 4^{+}$ percentage $<20 \%$ and a Specificity of $43.5 \%$, whereas it had a Sensitivity of $61.6 \%$ to detect patients with a $\mathrm{CD} 4^{+}$percentage $<15 \%$ and a Specificity of $44.4 \%$. For absolute $\mathrm{CD}^{+}{ }^{+} \mathrm{T}$-cell count, lowering the TLC cutoff value led to an increased Specificity, but decreased Sensitivity $[20,21]$. The other study on monitoring of highly active antiretroviral therapy (HAART) in developing countries reported that Where CD4 count is unavailable, TLC use has already been recommended for the timing of opportunistic infection prophylaxis in Latin America, Africa, and Asia. For example, in a cohort of HIV-positive south Indians, a $\mathrm{TLC}<1400$ cells $/ \mu \mathrm{l}$ is a good predictor of CD $4+\mathrm{T}$ count $<200$ cells $/ \mu \mathrm{l}$ and thus, an appropriate surrogate marker [22].

\section{Conclusion}

A total of 303 samples were collected in virology department of NPHL, collected blood sample were subjected to CD4, CD3 and TLC count within 6 hours of collection by BD Tritest CD3 FITC/CD4 PE/ CD45 per CP method. Among the 303 patients enrolled, 179(59.1\%) were male, $122(40.3 \%)$ were female and $2(0.7 \%)$ were third gender. The age range from 1 to 88 years (mean 31 years). Among 303 patient observed, $25.4 \%$ (77) had CD4 T cell count $<200$ and $6.3(19)$ had CD $4^{+}$ T-cell count $<50$, and $41.9 \%$ (127) had $\mathrm{CD} 4^{+}$count more than 350 cells/ $\mathrm{mm}^{3}$.

A TLC $<1400 \mathrm{cell} / \mathrm{mm}^{3}$ was found to have a maximal Sensitivity and Specificity for predicting a $\mathrm{CD} 4^{+} \mathrm{T}$ cell count $<200 \mathrm{cell} / \mathrm{mm}^{3}$. A TLC $<18,00$ cell $/ \mathrm{mm}^{3}$ was found to have a maximal combination of Sensitivity and Specificity for predicting a $\mathrm{CD} 4^{+} \mathrm{T}$ cell count of $<350$ cell $/ \mathrm{mm}^{3}$.

A CD3 $<1000 \mathrm{cell} / \mathrm{mm}^{3}$ was found to have a maximal Sensitivity and Specificity for predicting a CD4 ${ }^{+} \mathrm{T}$ cell count $<200 \mathrm{cell} / \mathrm{mm}^{3}$. A $\mathrm{CD} 3<1,300 \mathrm{cell} / \mathrm{mm}^{3}$ was found to have a maximal combination of Sensitivity and Specificity for predicting a CD4 ${ }^{+} \mathrm{T}$ cell count of $<350$ cell $/ \mathrm{mm}^{3}$.

\section{References}

1. Phillips AN, Lazzarin A, Gonzales-Lahoz, Clumeck N, Glauser MP, et al. (1996) Factors associated with the CD4+ lymphocyte count at diagnosis of acquired immunodeficiency syndrome. J clin Epidemiologic 49: 1253-1258.

2. UNAIDS (2006) Report on the Global Aids Epidemic.

3. Centers for Disease Control (CDC) (1987) Revision of the CDC surveillance case definition for acquired immunodeficiency syndrome. Council of State and Territorial Epidemiologists; AIDS Program, Center for Infectious Diseases. MMWR Morb Mortal Wkly Rep 36: 1S-15S.

4. WHO (2006) Enumeration of CD4 T Lymphocytes. Report of a Workshop Bangkok, Thailand.

5. Male D, Brostoff J, Roth DB, Roitt I (2006) Immunology. International edition (7thedn), Mosby Elsevier.

6. Mwamburi DM, Ghosh M, Fauntleroy J, Gorbach SL, Wanke CA (2005) Predicting CD4 count using total lymphocyte count: a sustainable tool for clinical decisions during HAART use. Am J Trop Med Hyg 73: 58-62.

7. Angelo AL, Angelo CD, Torres AJ, Ramos AM, Lima M, et al. (2007) Evaluating total lymphocyte counts as a substitute for CD4 counts in the follow up of AIDS patients. Braz J Infect Dis 11: 466-470.

8. Kamya MR, Semitala FC, Quinn TC, Ronald A, Njama-Meya D, et al. (2004) Total lymphocyte count of 1200 is not a sensitive predictor of CD4 lymphocyte count among patients with HIV disease in Kampala, Uganda. Afr Health Sci 4: 94-101.

9. (2007) BD Tritest CD3 FITC/CD4 PE/CD45 PerCP reagent. BD Biosciences Becton, Dickinson and Company, San Jose, CA, USA.

10. WHO (2005) Antiretroviral drugs for the treatment of HIV infection in adults and adolescents in resource-limited settings. Recommendations for a Public Health Approach (2005-2006 Revision): Brief Meeting Report. Guidelines Developing Group, Montreux, Switzerland.

11. Kumarasamy N, Mahajan AP, Flanigan TP, Hemalatha R, Mayer $\mathrm{KH}$, et al. (2002) Total lymphocyte count (TLC) is a useful tool for the timing of opportunistic infection prophylaxis in India and other resource-constrained countries. J Acquir Immune Defic Syndr 31: 378-383.

12. Daka D, Loha $E$ (2008) Relationship between total lymphocyte count (TLC) and CD4 count among peoples living with HIV, Southern Ethiopia: a retrospective evaluation. AIDS Res Ther 5: 26.

13. Post FA, Wood R, Maartens G (1996) CD4 and total lymphocyte counts as predictors of HIV disease progression. QJM 89: 505-508.

14. Fournier AM, Sosenko JM (1992) The relationship of total lymphocyte count to CD4 lymphocyte counts in patients infected with human immunodeficiency virus. Am J Med Sci 304: 79-82. 
Citation: Poudel S, Prajapati S, Prajapati BL, Gyawali R, Acharya S, et al. (2014) Utility of Total Lymphocyte Count as an Affordable Surrogate for CD4 Lymphocyte Count in HIV Infected Nepali Patients. J AIDS Clin Res 5: 290. doi:10.4172/2155-6113.1000290

15. Beck EJ, Kupek EJ, Gompels MM, Pinching AJ (1996) Correlation between total and CD4 lymphocyte counts in HIV infection: not making the good an enemy of the not so perfect. Int J STD AIDS 7: 422-428.

16. Bedell R, Heath KV, Hogg RS, Wood E, Press N, et al. (2003) Total lymphocyte count as a possible surrogate of CD4 cell count to prioritize eligibility for antiretroviral therapy among HIV-infected individuals in resource-limited settings. Antivir Ther 8: 379-384.

17. Gupta A, Gupte N, Bhosale R, Kakrani A, Kulkarni V, et al. (2007) Low sensitivity of total lymphocyte count as a surrogate marker to identify antepartum and postpartum Indian women who require antiretroviral therapy. J Acquir Immune Defic Syndr 46: 338-342.

18. Jacobson MA, Liu L, Khayam-Bashi H, Deeks SG, Hecht FM, et al. (2003) Absolute or total lymphocyte count as a marker for the CD4 T lymphocyte criterion for initiating antiretroviral therapy. AIDS 17: 917-919.
19. Blatt SP, Lucey CR, Butzin CA, Hendrix CW, Lucey DR (1993) Total lymphocyte count as a predictor of absolute CD4+ count and CD4+ percentage in HIVinfected persons. JAMA 269: 622-626.

20. Badri M, Wood R (2003) Usefulness of total lymphocyte count in monitoring highly active antiretroviral therapy in resource-limited settings. AIDS 17: 541 545.

21. van der Ryst E, Kotze M, Joubert G, Steyn M, Pieters H, et al. (1998) Correlation among total lymphocyte count, absolute CD4+ count, and CD4+ percentage in a group of HIV-1-infected South African patients. J Acquir Immune Defic Syndr Hum Retrovirol 19: 238-244.

22. Balakrishnan P, Solomon S, Kumarasamy N, Mayer KH (2005) Low-cost monitoring of HIV infected individuals on highly active antiretroviral therapy (HAART) in developing countries. Indian J Med Res 121: 345-355. 